\title{
Loss aversion in taste-based employee discrimination: Evidence from a choice experiment
}

\author{
Louis Lippens ${ }^{\mathrm{a}, \mathrm{b}, *}$, Stijn Baert ${ }^{\mathrm{a}, \mathrm{c}, \mathrm{d}, \mathrm{f}, \mathrm{f}, \mathrm{g}}$, Eva Derous ${ }^{\mathrm{a}}$ \\ ${ }^{a}$ Ghent University, Sint-Pietersplein 6, 9000 Ghent, Belgium \\ ${ }^{\mathrm{b}}$ Vrije Universiteit Brussel, Belgium \\ ${ }^{\mathrm{c}}$ University of Antwerp, Belgium \\ ${ }^{\mathrm{d}}$ Université catholique de Louvain, Belgium \\ e IZA, Germany \\ ${ }^{\mathrm{f}} \mathrm{GLO}$, Netherlands \\ ${ }^{g}$ IMISCOE, Netherlands
}

\section{A R T I C L E I N F O}

\section{Article history:}

Received 6 June 2021

Received in revised form 25 August 2021

Accepted 9 September 2021

Available online 17 September 2021

\section{JEL classification:}

J15

J71

C91

\section{Keywords:}

Taste-based discrimination

Employee discrimination

Loss aversion

Ethnicity

\begin{abstract}
A B S T R A C T
Using a choice experiment, we test whether taste-based employee discrimination against ethnic minorities is susceptible to loss aversion. In line with empirical evidence from previous research, our results indicate that introducing a hypothetical wage penalty for discriminatory choice behaviour lowers discrimination and that higher penalties have a greater effect. Most notably, we find that the propensity to discriminate is significantly lower when this penalty is loss-framed rather than gain-framed. From a policy perspective, it could therefore be more effective to financially penalise taste-based discriminators than to incentivise them not to discriminate.
\end{abstract}

(c) 2021 Elsevier B.V. All rights reserved.

\section{Introduction}

Taste-based discrimination is rooted in the idea that individuals are willing to (literally) pay a price to avoid contact with members of the (ethnic) minority group (Becker, 1971). In the specific case of taste-based employee discrimination, this means that discriminating employees would be willing to forego a percentage of their wage directly proportionate to their experienced distaste to avoid working alongside minority colleagues (Becker, 1971). ${ }^{1}$ Hedegaard and Tyran (2018) provide compelling empirical evidence for this proposition using a field experiment. The authors found that student workers from Denmark, who had perfect information about the productivity of their potential colleagues, were willing to waive up to eight per cent of their

\footnotetext{
* Corresponding author at: Ghent University, Sint-Pietersplein 6, 9000 Ghent, Belgium.

E-mail addresses: Louis.Lippens@UGent.be (L. Lippens), Stijn.Baert@UGent.be (S. Baert),Eva.Derous@UGent.be (E. Derous).

1 Oftentimes, it is the hiring and first-line managers who hire new employees, while also having to work together with them after the hiring decision. Therefore, the logic of employee discrimination also applies to these managers, who both act as co-workers and as representatives of the employer (e.g., in the hiring process).
}

wage to avoid working with a colleague of different ethnicity. However, this willingness to discriminate diminished as the price of doing so increased.

Insights from the behavioural economics literature suggest that representing a wage differential in terms of losses would have a greater (negative) effect on the willingness of employees to discriminate against minority colleagues, i.e. loss aversion, than when this difference is phrased in terms of gains (Kahneman et al., 1991; Novemsky and Kahneman, 2005). Based on this concept, one could thus expect that majority employees would be less inclined to accept a wage decrease to be able to collaborate with majority colleagues than they would be willing to increase their wage to work alongside minority colleagues (Kahneman et al., 1991).

If taste-based discriminators are loss averse, this could have particular policy implications. More specifically, these discriminators would then be more susceptible to losing money when engaging in discriminatory behaviour than gaining money by not discriminating. Therefore, when the choice is merely to penalise or reward, it could be more effective to impose financial sanctions to counteract discriminatory practices motivated by distaste than to subsidise or incentivise inclusion directly. However, this hypothesis has yet to be explored. 
Table 1

Factorial design $(2 \times 4)$ of the experiment.

\begin{tabular}{|c|c|c|c|c|c|c|c|c|c|c|}
\hline \multirow[t]{2}{*}{ Level (Condition) } & \multirow[t]{2}{*}{ Factor (Sub-condition) } & \multicolumn{3}{|c|}{$\begin{array}{l}\text { Company A } \\
75 \% \text { Flemish, low wage }\end{array}$} & \multicolumn{3}{|c|}{$\begin{array}{l}\text { Company B } \\
75 \% \text { Maghrebi, low wage }\end{array}$} & \multicolumn{3}{|c|}{$\begin{array}{l}\text { Company C } \\
75 \% \text { Maghrebi, high wage }\end{array}$} \\
\hline & & Ref. & $\Delta$ Wage & $\mathrm{E}$ (Wage) & Ref. & $\Delta$ Wage & E(Wage) & Ref. & $\Delta$ Wage & E(Wage) \\
\hline \multirow{4}{*}{ Gain } & EUR 50 & \multirow{4}{*}{2,150} & \multirow{4}{*}{+0} & \multirow{4}{*}{2,150} & \multirow{4}{*}{2,150} & \multirow{4}{*}{+0} & \multirow{4}{*}{2,150} & 2,150 & +50 & 2,200 \\
\hline & EUR 100 & & & & & & & 2,150 & +100 & 2,250 \\
\hline & EUR 150 & & & & & & & 2,150 & +150 & 2,300 \\
\hline & EUR 200 & & & & & & & 2,150 & +200 & 2,350 \\
\hline \multirow{4}{*}{ Loss } & EUR 50 & \multirow{4}{*}{2,350} & \multirow{4}{*}{-200} & \multirow{4}{*}{2,150} & \multirow{4}{*}{2,350} & \multirow{4}{*}{-200} & \multirow{4}{*}{2,150} & 2,350 & -150 & 2,200 \\
\hline & EUR 100 & & & & & & & 2,350 & -100 & 2,250 \\
\hline & EUR 150 & & & & & & & 2,350 & -50 & 2,300 \\
\hline & EUR 200 & & & & & & & 2,350 & -0 & 2,350 \\
\hline
\end{tabular}

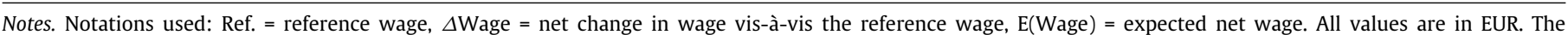

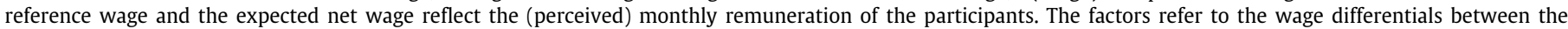
lowest and the highest expected net wage across the respective sub-conditions.

Current examples of labour market incentives include wage subsidy programmes, which are aimed at encouraging employers to hire employees from disadvantaged groups by contributing to their (initial) labour costs (OECD, 2020). In a recent meta-analysis, Butschek and Walter (2014) found that these wage subsidies have predominantly positive employment effects for immigrants in Europe. Moreover, in France, a recently established public policy called 'Emplois Francs' directly incentivises employers - who can receive up to EUR 15,000 over a three-year period for employing (minority) workers living in socially disadvantaged neighbourhoods - not to discriminate (Chareyron et al., 2021). Even though this form of subsidy may seem compelling to employers at first, Chareyron et al. (2021) found no positive long-term effects of this novel policy scheme on the employment of (minority) workers living in these neighbourhoods.

Conversely, non-discrimination legislation provides means to judicial bodies to sanction discriminators (Chopin and Germaine, 2015). These sanctions can take on different forms, such as dismissing the discriminator or imposing fines on the discriminator. The objective of fining discriminators in the labour market is evident: diminishing discriminatory behaviour and subsequently improving employment opportunities for minorities. There exists some evidence that hiring discrimination is lower when nondiscrimination laws allow for larger penalties (Neumark et al., 2019). However, there remains doubt on the effectiveness of financial sanctions in practice, because - specifically in the European context - (i) the litigation process is often complex and time-consuming, (ii) the amounts of the fines are relatively low, and (iii) the average time gap between the infraction and the legal decision is relatively high (Chopin and Germaine, 2015).

We constructed a choice experiment in which we assessed the trade-off between financially incentivising inclusion and penalising discrimination by examining the effect of loss aversion on taste-based employee discrimination against ethnic minorities. Previous empirical research on employee discrimination has mainly focused on interaction effects between hiring discrimination and intra-firm contact or collaboration between colleagues (see Lippens et al., 2020 for an overview; e.g., Weichselbaumer, 2017). Hence, evidence for employee discrimination was measured indirectly. We add to this literature by (i) directly examining collaboration preferences on the part of employees and (ii) evaluating whether penalising employee discrimination is more effective than incentivising non-discriminatory behaviour.

Our hypotheses are as follows. First, based on empirical evidence presented in the literature review of Lippens et al. (2020), we hypothesise that, on average, participants will prefer to work alongside ethnic majority colleagues vis-à-vis ethnic minority colleagues, ceteris paribus (H1). ${ }^{2}$ Second, in line with findings

\footnotetext{
2 Findings from Baert and De Pauw (2014), however, exemplify that is difficult to detect discrimination in a lab environment.
}

from Hedegaard and Tyran (2018), we expect that introducing a wage differential that penalises discriminatory choice behaviour will decrease the level of displayed discrimination (H2) and that higher (penalising) wage differentials will lead to more significant declines in discrimination (H3). Last, following the concept of loss aversion (Kahneman et al., 1991), we anticipate that the propensity to discriminate will be lower when the wage differential is framed in terms of losses versus gains (H4). We find empirical evidence for all four hypotheses.

\section{Method}

We report on the results of a scenario-based choice experiment conducted via the online survey platform Qualtrics, which took place within the framework of a broader research initiative on ethnic labour market discrimination in the fall of 2020 . In total, 413 students taking classes in economics and psychology at Ghent University in Flanders, Belgium, completed the choice experiment-391 observations were retained in our analyses (cfr. infra). The majority of the participants were born in Belgium ( $N=371,94.88 \%)$, were female $(N=283,72.38 \%)$ and had not yet attained a bachelor's degree $(N=305,78.01 \%)$. The average age of the participants was 20.19 years $(S D=3.47)$. To incentivise the students to participate, they were either granted two credits for research participation or instructed that participation would give them an advantage in answering exam questions about the research results.

The experiment was based on a factorial design with two levels (conditions: gain and loss) and four factors (sub-conditions: EUR 50, EUR 100, EUR 150, and EUR 200) and consisted of three parts: the scenario outline, a comprehension check, and a choice component (see Appendix A). Table 1 provides a matrix overview of the design. From the scenario, the participants learned that they had recently graduated and had received job offers from three different companies. Company A and B differed in terms of the teams' ethnic composition, while Company B and C differed concerning the expected net wage. The participants were randomly allocated to the conditions. In the gain condition, the participants would receive a monthly payroll bonus, which did not vary in time and was unaffected by their own or their team's productivity. The latter is critical to rule out second-order statistical discrimination as a potential discrimination mechanism (Neumark, 2012). ${ }^{3}$ The loss condition included a monthly recurring commuting cost, which the participant would have to pay out of pocket. To exclude the possible (perceived) side-

\footnotetext{
3 Second-order statistical discrimination constitutes unequal treatment based on group differences in the variance of productivity-related characteristics (Neumark, 2012). In our choice experiment, we decoupled the bonus from the team's performance. Hence, the distribution of the bonus should theoretically in the minds of our participants - not be linked to the team's ethnic composition. This is important, because, if the bonus would be endogenous to the team's
} 


\section{1a. Employee discrimination}

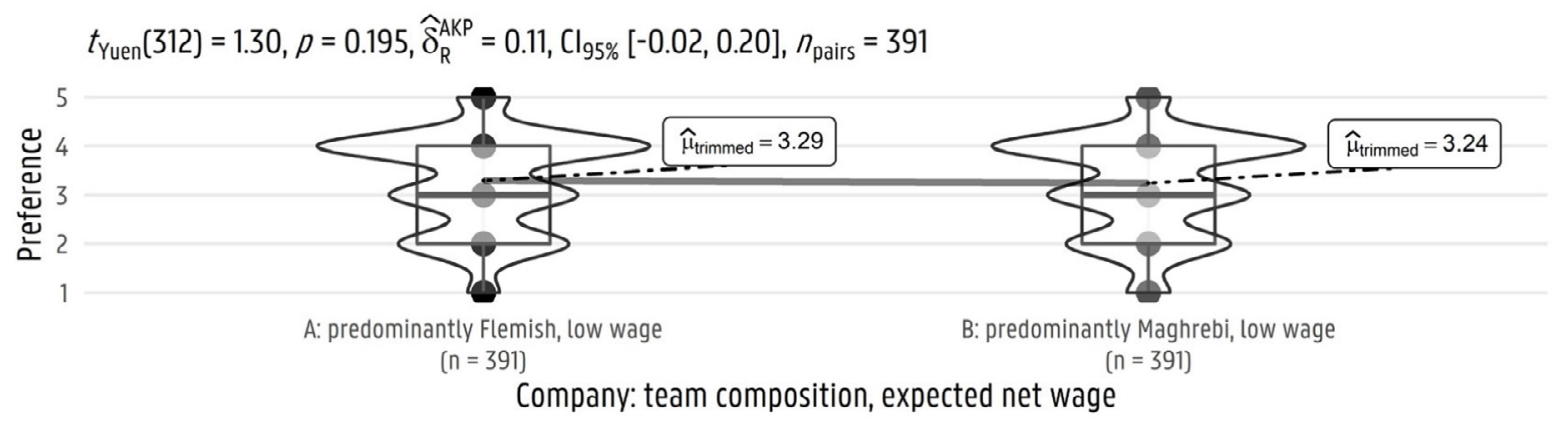

1b. Employee discrimination [controlled for high social desirability)

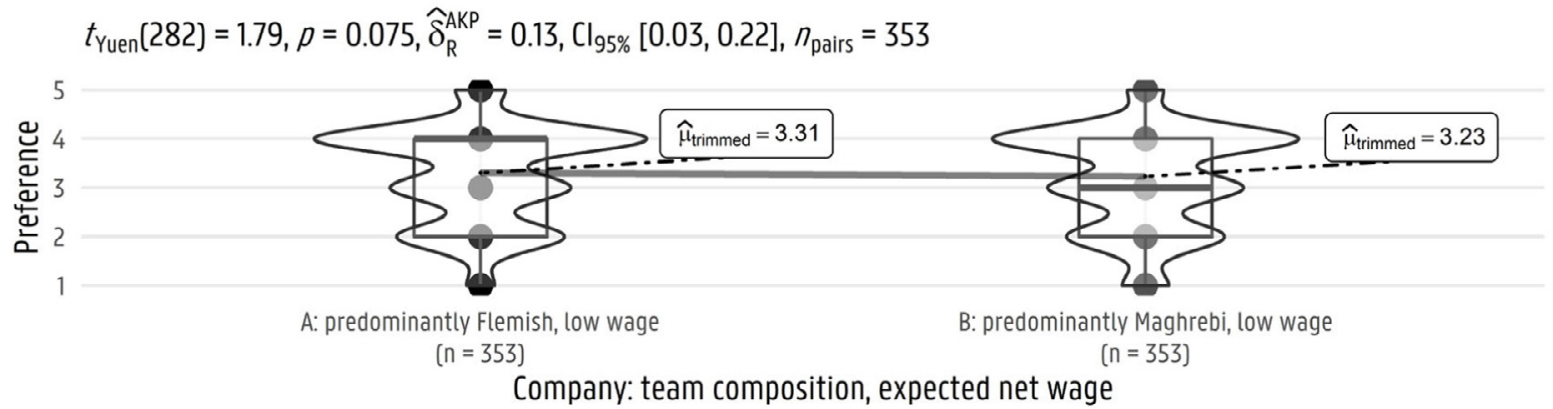

1c. Penalised employee discrimination

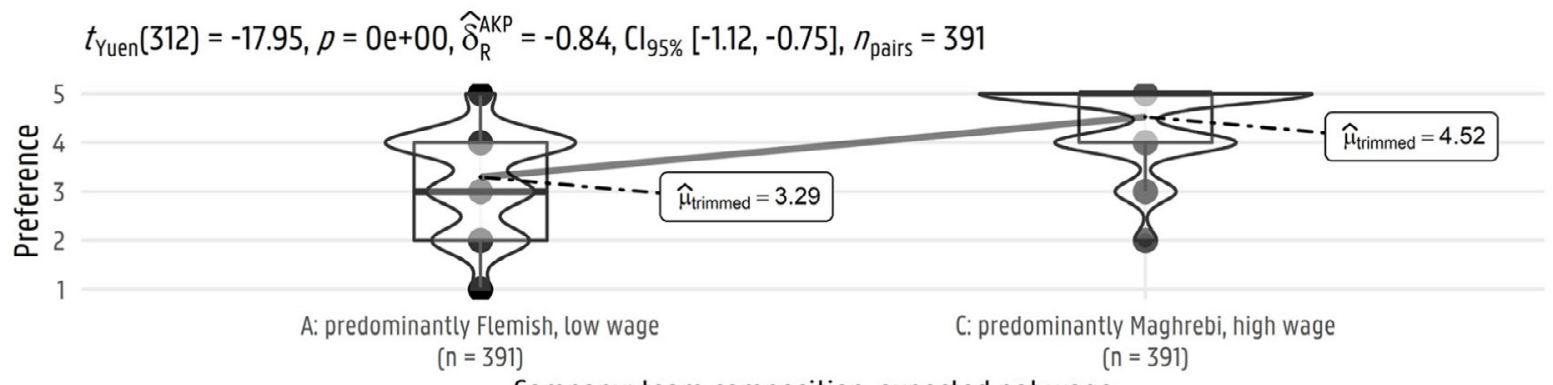

Company: team composition, expected net wage

\section{1d. Penalised employee discrimination (controlled for high social desirability)}

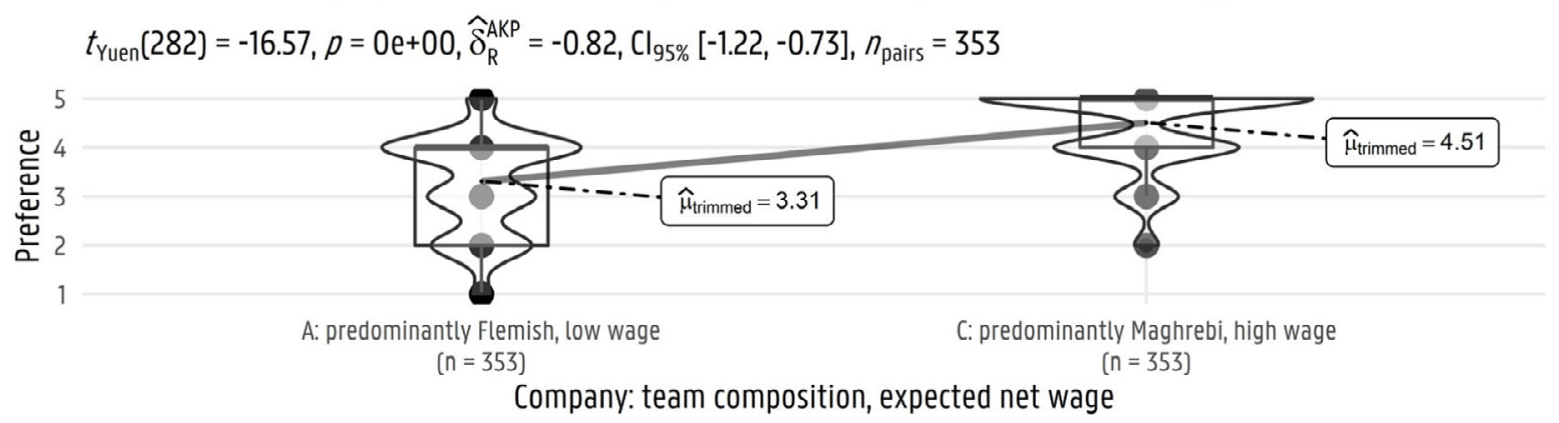

Fig. 1. Within-subject measures of (penalised) employee discrimination.

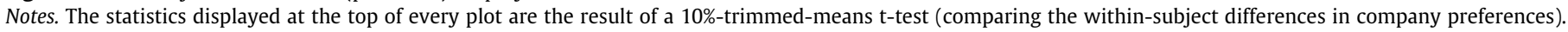

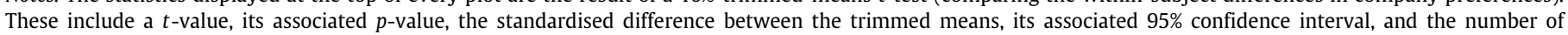
pairs in the comparison. The curved lines on the plots depict the smoothed density of the distribution of the preference scores.

effects of commuting, it was signalled to the participants that the differences in the commuting cost did not imply differences in

performance, some (risk-averse) participants may believe that the variability of the bonus might be greater when primarily working together with colleagues of the ethnic minority group. Differences in preferences could then be explained in terms of (second-order) statistical discrimination rather than taste-based discrimination. commuting time. The amount of the wage differential in the gain (loss) condition ranged from EUR 50 to EUR 200 relative to the reference wage of EUR 2,150 (EUR 2,350). ${ }^{4}$

\footnotetext{
4 The disparities between the wage differentials should provide sufficient
} sensitivity to detect differences in effects (see Hedegaard and Tyran, 2018). 

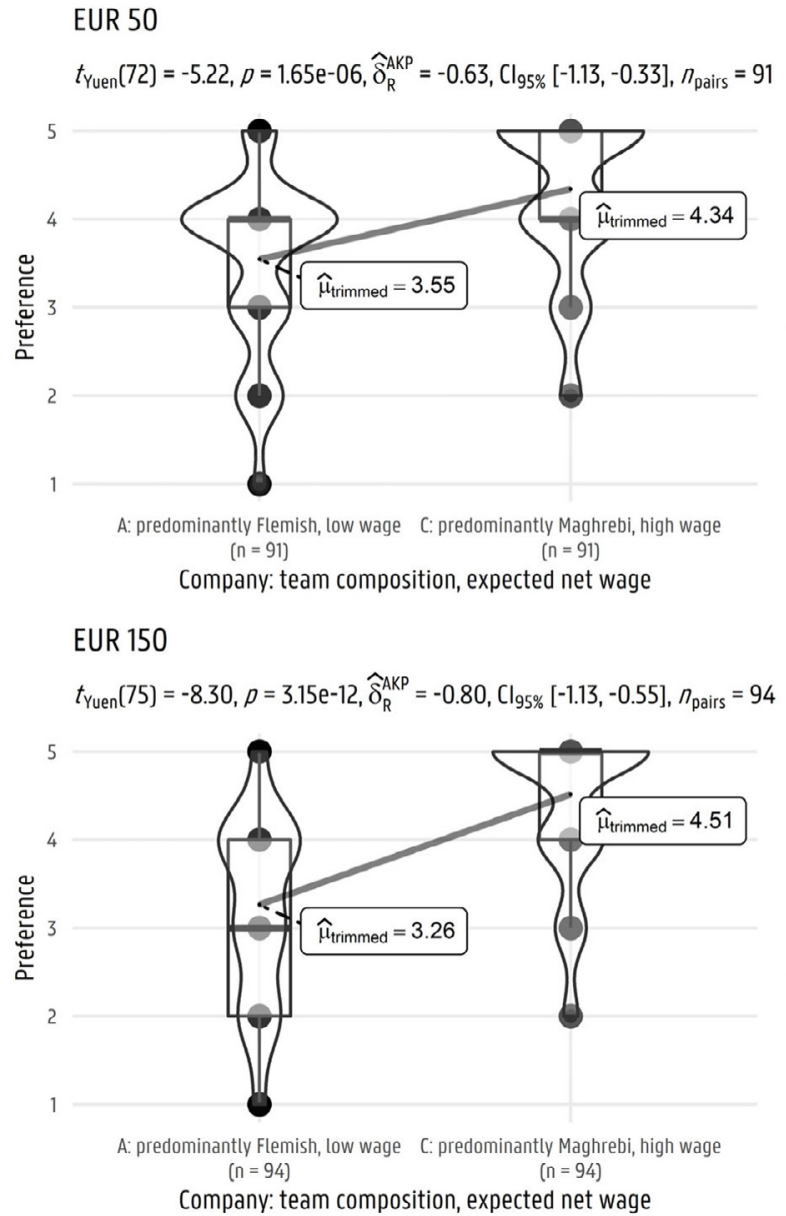

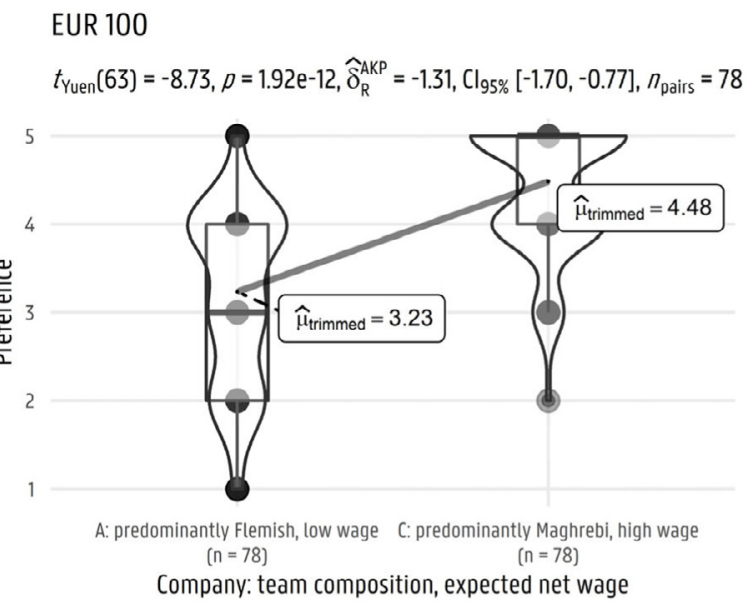

EUR 200

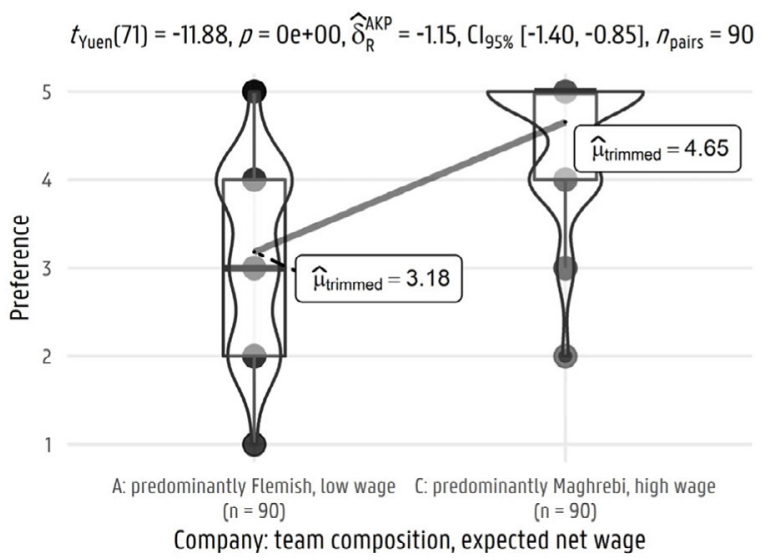

Fig. 2. Within-subject differences in penalised employee discrimination by wage differential.

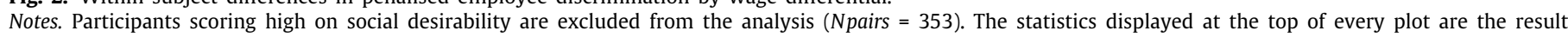

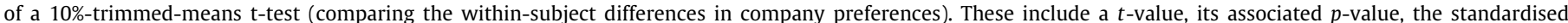

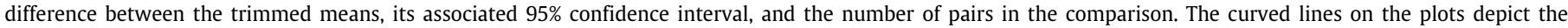
smoothed density of the distribution of the preference scores. The comparisons are presented in panels, grouped by sub-condition (i.e., wage differential).

To ensure that the final analysis included only those participants who fully comprehended the implications of their choices, all participants were presented with a comprehension check, which consisted of two questions about the scenario. Each question required the participants to calculate their potential net gain or loss. Participants who failed to answer both questions correctly were excluded from the analysis. Eventually, 391 valid observations remained (out of $413,94.67 \%$ ).

The choice component of the experiment comprised (i) a brief scenario outline, (ii) a tabulated overview of the company attributes, and (iii) a series of multiple-choice items on company preferences. The companies were displayed in random order to exclude order effects. The ethnic composition of the team was signalled by displaying four surnames. Three out of four surnames were typical of the Flemish majority (Maghrebi minority) group, and one surname was typical of the Maghrebi minority (Flemish majority) group. ${ }^{5}$ Eventually, each participant had to indicate their agreement with the statement 'I would like to work at [company name]' for each company on a five-point Likert

\footnotetext{
5 We focus on minorities from Maghreb origin because its Moroccan subgroup forms one of the largest, most recently migrated ethnic groups in Belgium, and is often the object of intra-country discrimination research (Baert et al., 2017; Martens, 2017).
}

scale, which constituted our measure of taste-based employee discrimination. ${ }^{6}$

We recognise three limitations concerning our method. First, student participants might not be representative of the workforce at large. Nonetheless, the participants have most likely already co-operated with others in a professional work environment (e.g., a student job). Second, despite signalling to the participants that an increase in the commuting cost did not entail additional commuting time, some participants might implicitly associate an extra burden with this cost. Third, our choice experiment was based on a hypothetical scenario. Therefore, the participants' choices did not entail real (financial) risk. However, previous research has demonstrated that the effect of loss aversion also holds in riskless contexts (Kahneman et al., 1991; Novemsky and Kahneman, 2005).

\section{Results}

Fig. 1 depicts the within-subject differences in company preferences. We derive two measures of discrimination from these

\footnotetext{
6 We recognise that some participants might have (erroneously) believed that, if they would be working together with ethnic minority colleagues, they should compensate for the lower productivity of these colleagues. Therefore, it cannot be unconditionally ruled out that the discriminatory choice behaviour we found could, to some extent, be explained by statistical discrimination. Nonetheless, it is more likely that the uncovered discrimination is taste-based in nature.
} 


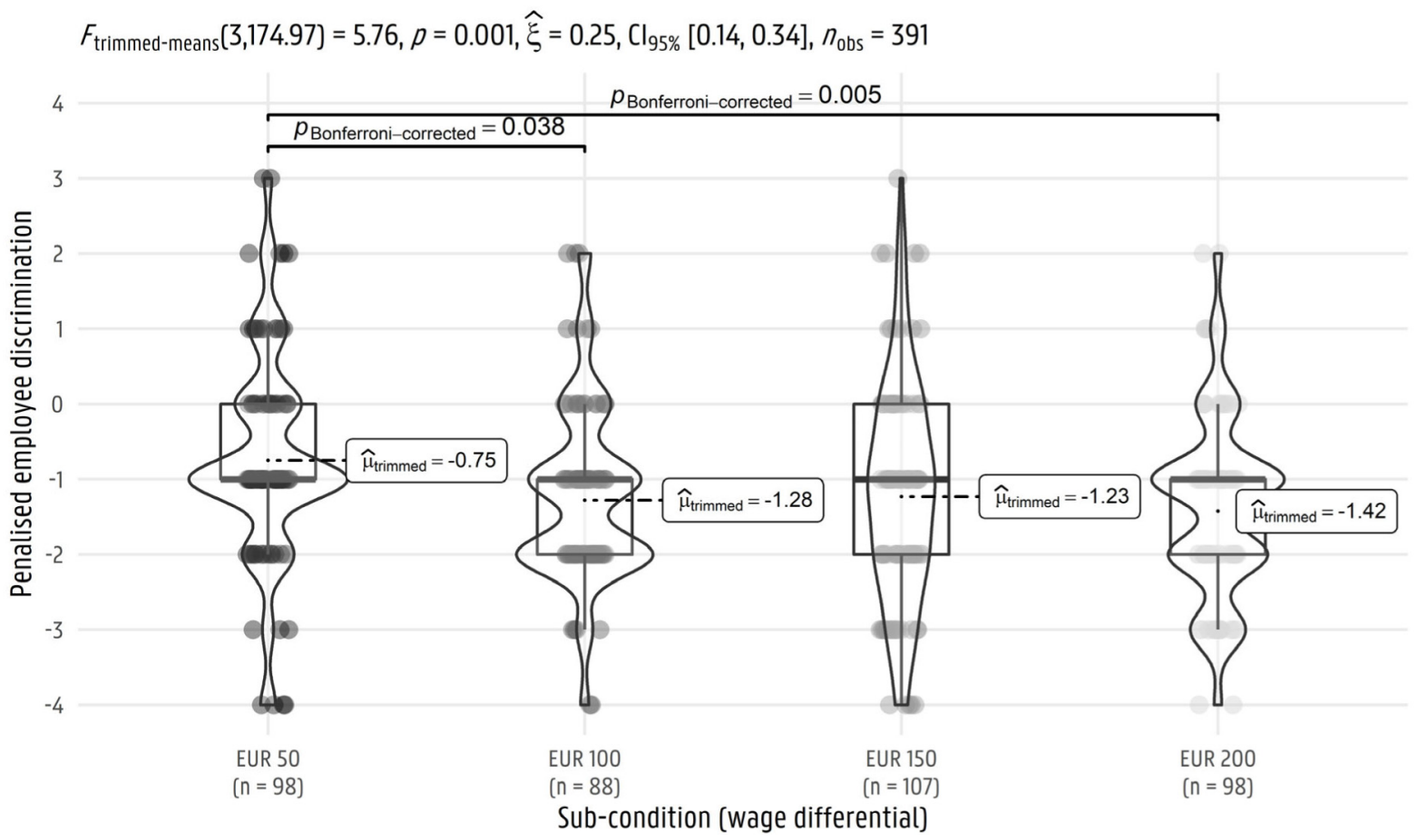

Fig. 3. Between-subject differences in penalised employee discrimination by sub-condition.

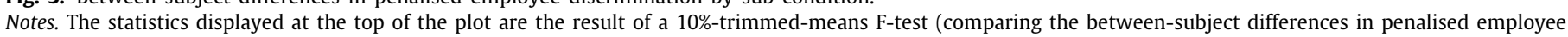

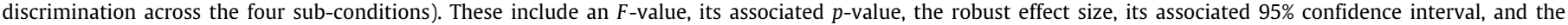

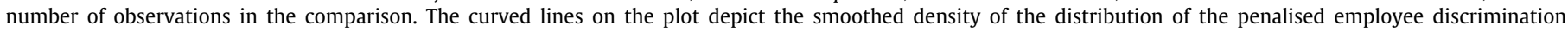

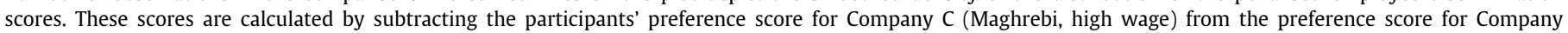
A (Flemish, low wage).

preferences: 'employee discrimination' and 'penalised employee discrimination'.7 Employee discrimination is calculated by subtracting the preference score for Company B (Maghrebi, low wage) from the preference score for Company A (Flemish, low wage). Similarly, we calculate penalised employee discrimination by subtracting the preference score for Company $C$ (Maghrebi, high wage) from the preference score for Company A (Flemish, low wage). Using a robust, trimmed-means t-test to compare differences in preferences between Company A (Flemish, low wage) and Company B (Maghrebi, low wage), we find no statistically significant evidence for employee discrimination $\left(\Delta_{10 \% \text {-trimmed-means }}\right.$ $\left.=0.05, t_{\text {Yuen }}=1.30, p=0.195\right) .{ }^{8}$ However, socially desirable choice behaviour could lead to an underestimation of the actual discrimination. When we filter out participants with average scores higher than 4 (out of 5) on Strahan and Gerbasi's (1972) 10-item social desirability scale, we indeed find weak, marginally significant evidence for employee discrimination ( $\Delta_{10 \% \text {-trimmed-means }}=0.08, t_{\text {Yuen }}=1.79, p=0.075$ ). In addition, the $95 \%$ confidence interval of the robust standardised difference excludes zero $\left(\delta_{R}^{A K P}=0.13, C I_{95 \%}=[0.03,0.22]\right)$. This is evidence in favour of H1. Leaving out participants who were born (or whose (grand)mother was born) in a foreign country does not significantly alter these results.

Conversely, when a wage differential that penalises discriminatory choice behaviour is imposed, we find that participants, on

\footnotetext{
7 All figures were created using Patil's (2021) 'ggstatsplot' package for R.

8 Because the normality of the distribution of the variables of interest could not be assumed, we use robust, $10 \%$-trimmed-means tests - as recommended by Wilcox (2012) - to reduce the effects of outliers, while retaining sufficient observations to preserve statistical power. This means that we exclude the $10 \%$ largest and $10 \%$ smallest preference scores from the sample distribution and statistically compare the means (of the remaining, middle $80 \%$ of the sample) of the different groups.
}

average, prefer Company C (Maghrebi, high wage) over Company A (Flemish, low wage; $\Delta_{10 \% \text {-trimmed-means }}=1.23$, $t_{\text {Yuen }}=-17.95$, $p<0.001)$. This finding is robust when we control for high social desirability $\left(\Delta_{10 \% \text {-trimmed-means }}=1.20, t_{\text {Yuen }}=-16.57\right.$, $p<0.001$ ). Moreover, Fig. 2 illustrates that the effect of the discrimination penalty on employee discrimination (controlled for high social desirability) persists irrespective of the amount of the wage differential. We thus find compelling evidence for $\mathbf{H 2}$.

Furthermore, using a trimmed-means F-test, we find empirical evidence in favour of H3. Fig. 3 illustrates that different penalties result in various levels of penalised employee discrimination $\left(F_{10 \% \text {-trimmed-means }}=5.76, p=0.001\right)$. More specifically, participants who have to hypothetically forego EUR 100 $\left(\psi_{\text {estimate }}=0.53, p_{\text {Bonferroni-corrected }}=0.038\right)$ or EUR $200\left(\psi_{\text {estimate }}=\right.$ $0.68, p_{\text {Bonferroni-corrected }}=0.005$ ) are significantly less inclined to discriminate against Maghrebi minorities than participants who only have to forfeit EUR $50 .{ }^{9}$ In contrast, the difference between the EUR 150 and EUR 50 wage differential is not statistically significant ( $\psi_{\text {estimate }}=0.48, p_{\text {Bonferroni-corrected }}=0.315$ ).

Finally, using a trimmed-means t-test to evaluate the betweensubject effect of the experimental conditions, we find empirical evidence for H4. Fig. 4 illustrates that, when the wage differential is framed in terms of a loss, participants show significantly lower levels of penalised employee discrimination than when

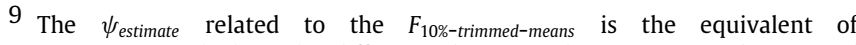

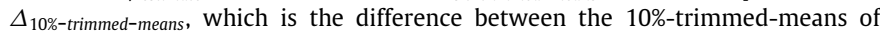
two groups in a pair-wise comparison. For example, if we compare the means of two of the four wage differentials (i.e., EUR 50 and EUR100) the associated difference in trimmed-means or $\psi_{\text {estimate }}$ is equal to 0.53 . In addition, we use the conservative Bonferroni correction to adjust the p-values for multiple (pairwise) hypothesis testing (Wilcox, 2012). This correction consists of multiplying the initial p-values by the number of comparisons. Applying less conservative corrections, such as Holm's correction, does not significantly alter our results or their interpretation.
} 


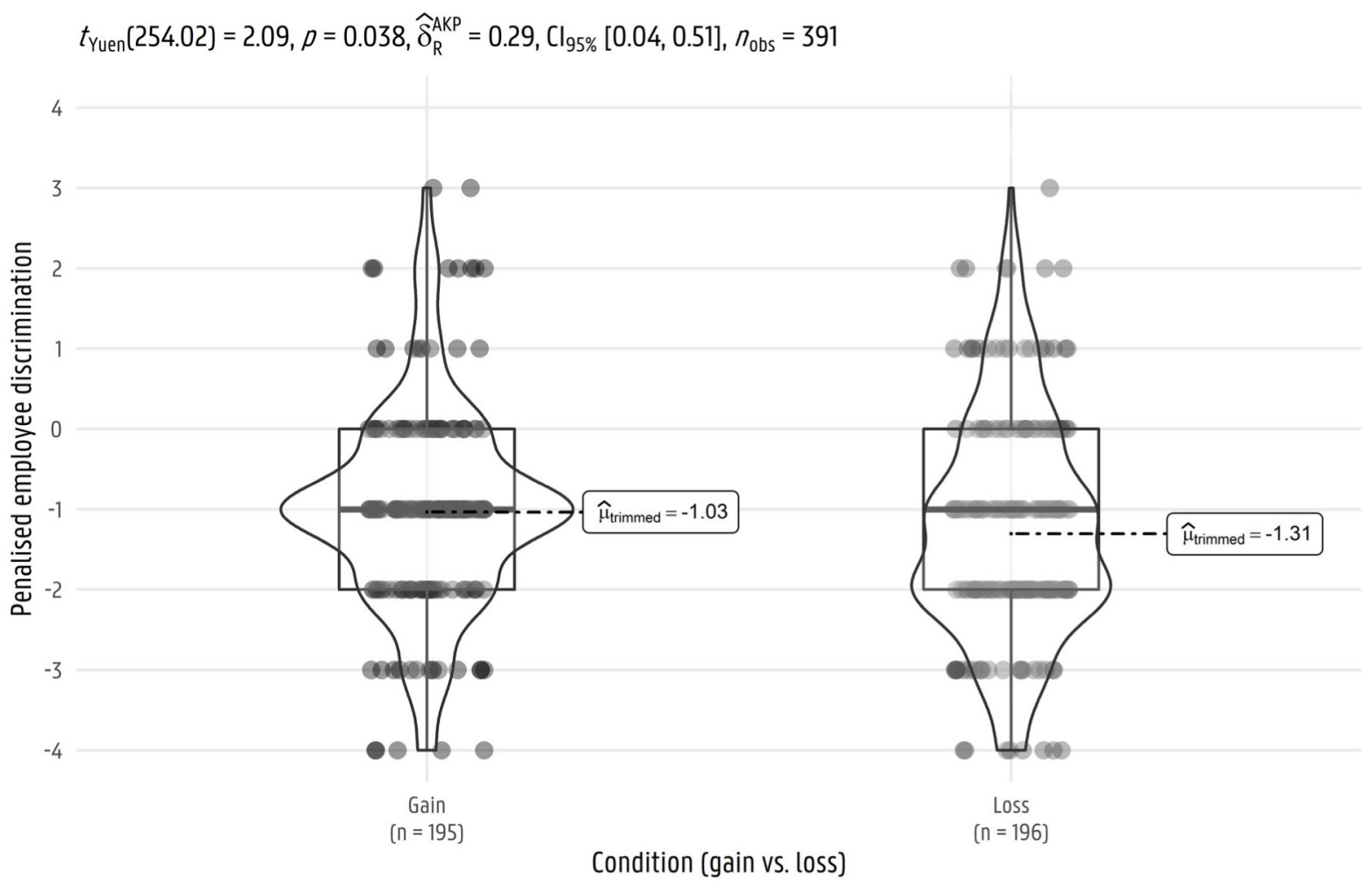

Fig. 4. Between-subject differences in penalised employee discrimination by condition.

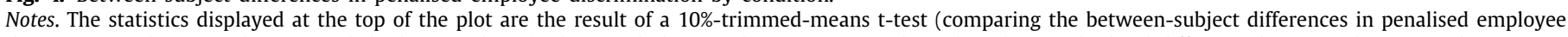

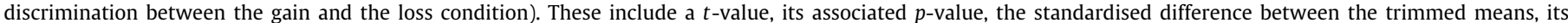

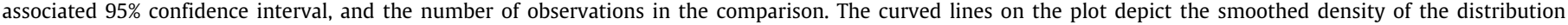

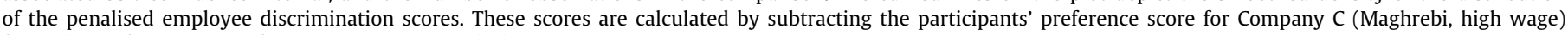
from the preference score for Company A (Flemish, low wage).

this differential is framed in terms of a gain $\left(\Delta_{10 \% \text {-trimmed-means }}=\right.$ $0.28, t_{\text {Yuen }}=2.09, p=0.038$ ). Importantly, we find that the effect of loss aversion on penalised employee discrimination persists when sociodemographic characteristics (e.g., migration background) and social desirability are controlled (see Appendix A).

\section{Conclusion}

In this study, we reported on a choice experiment to test whether taste-based employee discrimination is affected by loss aversion. Our results suggested that - controlling for social desirability - participants, on average, expressed a slight preference to work alongside ethnic majority colleagues vis-à-vis ethnic minority colleagues. However, this preference was reversed when a penalty (in the form of a wage differential) for discriminatory choice behaviour was introduced. In addition, the preference to work alongside ethnic minority colleagues increased as the penalty heightened. Most remarkably, even though both gainand loss-framed penalties reduced discriminatory preferences, the propensity to discriminate was significantly lower when the penalty was framed in terms of losses versus gains.

From a policy perspective, this means that fining taste-based discriminators for their unwillingness to collaborate with ethnic minorities is potentially more effective than directly incentivising them not to discriminate. Policymakers could act on these findings. This encompasses removing existing barriers (e.g., the complexity of the litigation process, the limited amount of the fines, and the considerable time lag between infractions and legal decisions) that hinder the effective application of non-discrimination legislation. Yet, most importantly, this entails focussing at least as actively on proportionately sanctioning clear cases of (tastebased) discrimination as on implementing established labour market incentives, such as wage subsidy programmes.

\section{Ethical approval}

This study is part of the interdisciplinary EdisTools project, which is centred around the development of tools to explain and reduce ethnicity-based (labour market) discrimination. Prior ethical approval for this research project was obtained from the ethics committee of the Faculty of Political and Social Sciences at Ghent University. Additional ethical approval for this noninterventional survey study was not required, since - in line with the ethical code of the Faculty of Economics and Business Administration and the Faculty of Psychological and Educational Sciences at Ghent University, where the research took place ex ante ethical approval of survey research which is based upon prior and informed consent is not obligatory.

\section{Informed consent from participants}

Informed consent was obtained in digital, written form prior to the start of the experiment. The data used in this study were pseudonymised before the analysis.

\section{Consent to publish}

Participants were informed about the general aim of the study. Due to the nature of the experiment, participants could not be a priori informed about the study's exact objective. Consent to use the participants' data for research purposes was obtained prior to the start of the experiment. Participants were extensively debriefed after the study was finalised. 


\section{Funding}

The study was conducted in the context of the EdisTools project. EdisTools is funded by Research Foundation - Flanders (Strategic Basic Research, S004119N).

\section{CRediT authorship contribution statement}

Louis Lippens: Conceptualisation, Formal analysis, Created the tables, figures and supplementary materials, Developing the methods used in the study, Writing - original draft, Writing review \& editing. Stijn Baert: Developing the methods used in the study, Supervised the data collection process, Writing - review \& editing. Eva Derous: Supervised the data collection process, Writing - review \& editing.

\section{Declaration of competing interest}

The authors declare that they have no known competing financial interests or personal relationships that could have appeared to influence the work reported in this paper.

\section{Data availability}

In line with the conditions outlined in the data management plan of the EdisTools project, of which this study is a part, the anonymised data will be made available after five years following the end of the research project. This approach guarantees the research team's possibilities to fully exploit the data for scientific valorisation and to obtain academic qualifications. Minimal, anonymised data will be unconditionally made available upon request but solely to replicate the study's findings.

\section{Acknowledgements}

We are thankful to Stijn Schelfhout for his support during the data collection process, to Fanny D'hondt for her role as a sounding board and to Eline Moens for her valuable feedback. We also appreciate the insightful comments of the participants in the Centre for the Social Study of Migration and Refugees (CESSMIR) Research Day and the Faculty of Economics and Business Administration (FEB) Research Day on the preliminary results of our study.

All authors approved the version of the manuscript to be published.

\section{Appendix A. Supplementary material}

Supplementary material related to this article can be found online at https://doi.org/10.1016/j.econlet.2021.110081.

\section{References}

Baert, S., Albanese, A., du Gardein, S., Ovaere, J., Stappers, J., 2017. Does work experience mitigate discrimination? J. Econ. Lett. 155, 35-38. http://dx.doi. org/10.1016/j.econlet.2017.03.011.

Baert, S., De Pauw, A.-S., 2014. Is ethnic discrimination due to distaste or statistics? Econom. Lett. 125 (2), 270-273. http://dx.doi.org/10.1016/j.econlet. 2014.09.020.

Becker, G., 1971. The Economics of Discrimination. University of Chicago Press, Chicago.

Butschek, S., Walter, T., 2014. What active labour market programmes work for immigrants in europe? A meta-analysis of the evaluation literature. IZA J. Migr. 3 (1), 48. http://dx.doi.org/10.1186/s40176-014-0023-6.

Chareyron, S., Challe, L., L'Horty, Y., Petit, P., 2021. Can subsidies paid directly to employers reduce residential discrimination in employment? An assessment based on serial field experiments. Urban Stud. http://dx.doi.org/10.1177/ 00420980211006033

Chopin, I., Germaine, C., 2015. Developing Anti-Discrimination Law in Europe: The 28 EU Member States, the Former Yugoslav Republic of Macedonia, Iceland, Liechtenstein, Norway and Turkey Compared. European Commission, http://dx.doi.org/10.2838/94057.

Hedegaard, M.S., Tyran, J.-R., 2018. The price of prejudice. Am. Econ. J.: Appl. Econ. 10 (1), 40-63. http://dx.doi.org/10.1257/app.20150241.

Kahneman, D., Knetsch, J.L., Thaler, R.H., 1991. Anomalies: The endowment effect, loss aversion, and status quo bias. J. Econ. Perspect. 5 (1), 193-206. http://dx.doi.org/10.1257/jep.5.1.193.

Lippens, L., Baert, S., Ghekiere, A., Verhaeghe, P.-P., Derous, E., 2020. Is labour market discrimination against ethnic minorities better explained by taste or statistics? A systematic review of the empirical evidence. In: IZA Discussion Paper Series. 13523.

Martens, A., 2017. Moroccan migration in Belgium's labor policy and labor market. In: Timmerman, C., Fadil, N., Goddeeris, I., Clycq, N., Ettourki, K. (Eds.), Moroccan Migration in Belgium: More than 50 Years of Settlement. Leuven University Press, Leuven (Belgium), pp. 87-104. http://dx.doi.org/10. 2307/j.ctt21c4s72.7.

Neumark, D., 2012. Detecting discrimination in audit and correspondence studies. J. Hum. Resour. 47 (4), 1128-1157. http://dx.doi.org/10.3368/jhr.47.4. 1128.

Neumark, D., Burn, I., Button, P., Chehras, N., 2019. Do state laws protecting older workers from discrimination reduce age discrimination in hiring? Evidence from a field experiment. J. Law Econ. 62 (2), 373-402. http://dx.doi.org/10. 1086/704008.

Novemsky, N., Kahneman, D., 2005. The boundaries of loss aversion. J. Mar. Res. 42 (2), 119-128. http://dx.doi.org/10.1509/jmkr.42.2.119.62292.

OECD, 2020. Diversity policies in the OECD and evidence on their effectiveness. In: OECD (Ed.), All HandS in? Making Diversity Work for All, first ed. OECD Publishing, Paris, pp. 39-59. http://dx.doi.org/10.1787/efb14583-en.

Patil, I., 2021. Visualizations with statistical details: The 'ggstatsplot' approach. J. Open Sour. Softw. 6 (61), 3167. http://dx.doi.org/10.21105/joss.03167.

Strahan, R., Gerbasi, K.C., 1972. Short, homogeneous versions of the marlowe-crowne social desirability scale. J. Clin. Psychol. 28 (2), 191-193. http://dx.doi.org/10.1002/1097-4679(197204)28:2\{<\}191::AIDJCLP2270280220\{>\}3.0.CO;2-G.

Weichselbaumer, D., 2017. Discrimination against migrant job applicants in Austria: An experimental study. Ger. Econ. Rev. 18 (2), 237-265. http: //dx.doi.org/10.1111/geer.12104.

Wilcox, R., 2012. Introduction To Robust Estimation and Hypothesis Testing. vol. 201, Elsevier Academic Press, Amsterdam, http://dx.doi.org/10.1016/C20100-67044-1. 